\title{
Comparison of the Biodegradation of n-alkanes and Readily Biodegradable Substrates Using Open Mixed Culture under Aerobic, Anoxic and Anaerobic Conditions
}

\author{
Chukwuemeka Uzukwu* , Davide Dionisi \\ Materials and Chemical Engineering Group, School of Engineering, University of Aberdeen, Aberdeen, AB24 2UE, UK \\ *Corresponding author: chukwuemeka.uzukwu13@aberdeen.ac.uk
}

\begin{abstract}
This study has investigated the biodegradation of n-alkanes using open mixed cultures in batch tests. Biodegradation of n-C12, C14, C16, C18, C20 was investigated using a respirometric method and compared with the biodegradation of the readily biodegradable substrates glucose, acetic acid and ethanol. Experiments were performed in small-scale bioreactors under various conditions, i.e. aerobic, anoxic with nitrate and completely anaerobic conditions, using two different sources of open mixed microbial cultures. Under aerobic conditions all the readily biodegradable substrates and hydrocarbons were removed, although the acclimation time was longer for the hydrocarbons (3-5 days) than for the readily biodegradable substrates (1-2 days). No significant effect on the hydrocarbon concentration on biodegradation was observed in the concentration range 0.5-5 g/l. Under anoxic conditions, both the readily biodegradable substrates and the hydrocarbons were removed using nitrate as electron acceptor. However, the acclimation time for the hydrocarbons under anoxic conditions (20-25 days) was much longer than under aerobic conditions. Under both aerobic and anoxic conditions, once acclimation with the hydrocarbons was completed, the microorganisms were immediately able to remove a second spike of the substrate without acclimation. Under anaerobic conditions, no activity was observed with the hydrocarbons over a period of 150 days, while the mixed culture was able to remove glucose and convert it to volatile fatty acids. Under aerobic conditions, the dissolved oxygen consumption data was mathematically modelled using Monod kinetics to obtain biokinetic parameters. Good fittings between the model and the experimental data was obtained and the biodegradation of hydrocarbons was characterised by higher values of the parameter $\mathrm{K}_{\mathrm{S}}$ compared to the readily biodegradable substrates. The results of this study showed that the open mixed microbial cultures contained diverse microorganisms capable of utilizing both liquid and solid n-alkanes under aerobic and anoxic conditions.
\end{abstract}

Keywords: biodegradation, n-alkanes, mixed culture, aerobic, anoxic, anaerobic, respirometry

Cite This Article: Chukwuemeka Uzukwu, and Davide Dionisi, "Comparison of the Biodegradation of n-alkanes and Readily Biodegradable Substrates Using Open Mixed Culture under Aerobic, Anoxic and Anaerobic Conditions.” International Journal of Environmental Bioremediation \& Biodegradation, vol. 5, no. 2 (2017): 65-76. doi: 10.12691/ijebb-5-2-5.

\section{Introduction}

The extensive use of petroleum components or hydrocarbons as fuels and chemicals has resulted to the introduction of these compounds into the environment. The exploration and production activities, refining processes, transport and storage of crude oil and petroleum products have often led to leaks and accidental spills or discharge of petroleum contaminating soils and water systems. Man-made activities resulting to soil and marine contamination is a worldwide environmental concern. Reports on contamination incidents published in 2007 in the UK shows that hydrocarbon related contamination made-up about $12 \%$ of the serious contamination incidents $[1,2]$. Alkanes make up a substantial portion of petroleum hydrocarbons and are significant contaminant of oil spills. The biodegradation of alkanes under aerobic conditions has been extensively reported in literature using pure cultures of bacteria, molds and yeasts belonging to thirty genera of microorganisms which are widely distributed in the environment [3]. As an alternative to pure cultures, the use of open mixed microbial cultures can be an attractive approach for n-alkane biodegradation because open mixed cultures are based on natural inocula with a high microbial diversity which can utilize a wide variety of substrates under non-sterile conditions. The biodegradation of n-alkanes under anoxic (i.e. using nitrate as electron acceptor in the absence of oxygen) and anaerobic (no external electron acceptors) conditions is equally important since oil spills have also occurred in underground storage tanks and aquifers where there is little or no molecular oxygen. Therefore, knowledge of n- 
alkane biodegradation under such conditions is important to be able to assess and predict the efficiency of bioremediation applications. The use of nitrate to remediate hydrocarbon contamination has been proposed as a bioremediating approach under anoxic conditions [4].

In the biodegradation of organic compounds, one important factor is the biodegradation rate. Kinetic models ranging from first-order decay rates [5] to more complicated models [6,7] have been developed to describe hydrocarbon biodegradation rates. The most commonly used mathematical models for biodegradation is the Monod expression [8] which contains two parameters $\left(\mu_{\max }\right.$ and $K_{s}$ ) and the determination of the biodegradation kinetics requires quantifying these parameters together with the growth yield $\mathrm{Y}$ [9]. As far as the experimental measurement of biodegradation rates is concerned, the use of respirometric techniques (electron acceptor consumption) has been gaining a lot of interest since the introduction of automated respirometers. Previous studies have shown that intrinsic kinetic parameters can be estimated from respirometric data obtained during the biodegradation of organic compounds [10]. The use of non-linear curve fitting techniques to such data i.e. oxygen consumption data can be used to achieve parameter estimates. Though some studies have been undertaken to measure the biodegradation of insoluble organic compounds by measuring the consumption of oxygen [11], to our knowledge, no detailed respirometric study on the biodegradation kinetics of n-alkanes and hydrocarbons in general using open mixed culture has been reported.

The first aim of this study was to obtain experimental data on the biodegradation of hydrocarbons using open mixed cultures under aerobic, anoxic and anaerobic conditions. The biodegradation of hydrocarbons has been compared with the biodegradation of readily biodegradable substrates (glucose, acetic acid and ethanol) using the same cultures. The second aim of this study was to measure the kinetic parameters of the Monod model that describe the aerobic biodegradation of the hydrocarbons and of the readily biodegradable substrates.

\section{Materials and Methods}

Microorganisms. Two different undefined mixed microbial cultures were used for this research. One was a mixed consortium obtained from a sludge taken from an anaerobic digestion (AD) plant in Gask, Turriff, Aberdeenshire, UK whose VSS concentration was $(22.7 \pm 0.4) \mathrm{g} / \mathrm{l}$. The inoculum was obtained from a suspended growth anaerobic digester operated under strictly anaerobic conditions at 50 days residence time. The temperature conditions of the digester were maintained between $38^{\circ} \mathrm{C}$ and $40^{\circ} \mathrm{C}$. The various feedstocks fed into the digester are meat processing wastes, maize silage, fish processing wastes and chicken feathers. The AD sludge used in this study contained facultative anaerobes (microorganisms active in the presence and absence of free molecular oxygen i.e. Escherichia coli, Bacillus sp etc). The second source was a soil obtained from an agricultural site (Craibstone in Aberdeenshire, UK) $(0.115 \pm 0.003 \mathrm{~g}$ of $\mathrm{VSS} / \mathrm{g}$ of soil). Bartram et al used soil $\mathrm{pH}$ (between the range of 4.5 - 7.5) to identify about 25 different bacteria taxa present in the
Craibstone experimental farm soil samples. Their methods which included next-generation sequencing of bacterial $16 \mathrm{~S}$ rRNA genes showed that Acidobacteria, Alphaproteobacteria, Verrucomicrobia and Gamma-proteobacteria were the higher taxonomic bacterial groups present in the Craibstone experimental farm soil. For detailed analysis of their methods, refer to Bartram et al [12].

Culture media. The standard mineral salt medium for aerobic and anaerobic conditions contained per litre of distilled water: $\mathrm{NH}_{4} \mathrm{Cl}$, 3g; $\mathrm{K}_{2} \mathrm{HPO}_{4}$, 34.8g; $\mathrm{NaH}_{2} \mathrm{PO}_{4}$, 24g; $\mathrm{MgCl}_{2} .6 \mathrm{H}_{2} \mathrm{O}, 0.05 \mathrm{~g} ; \mathrm{CaCl}_{2} \cdot 6 \mathrm{H}_{2} \mathrm{O}, 0.035 \mathrm{~g}$; thiourea, 0.02g. Denitrifying condition was established by adding $1 \mathrm{~g}$ of $\mathrm{NaNO}_{3}$ to each litre of mineral salt medium.

Test compounds. Five straight-chain aliphatic hydrocarbons (n-dodecane (C12), n-tetradecane (C14), n-hexadecane (C16), n-octadecane (C18) and n-eicosane (C20)) were purchased from Sigma-Aldrich with over 95\% purity all in analytical grade. Readily biodegradable compounds (glucose, acetic acid and ethanol) were also purchased from Sigma-Aldrich all in analytical grade.

Studies in batch culture. Two different set-ups were employed for the aerobic biodegradation tests and were designed to supply oxygen from air to the bioreactors (bottles) through diffusion. The first set-up was for the acclimation phase where a Wheaton lab media bottle (working volume $250 \mathrm{ml}$ ) with rubber lined cap was used as the bioreactor on a VELP Scientifica multi-magnetic stirrer. The bioreactors were open and set-up in triplicates for each of the substrates (spiked at a concentration of 0.5 or $5 \mathrm{~g} / \mathrm{l})$. The soil used was homogenized by sieving the sample with a sieve of $125 \mu \mathrm{m}$ porosity. $0.125 \mathrm{~g}$ of homogenized (dry) soil was used to give an initial concentration of $0.08 \mathrm{~g} \mathrm{VSS} / \mathrm{l}$ of inoculum concentration. For the experiments with $\mathrm{AD}$ inoculum, the sludge was filtered with a filter paper of $6 \mu \mathrm{m}$ porosity and $5 \mathrm{ml}$ of the filtrate was used to achieve the same inoculum concentration as in the soil bioreactors. The bottles were stirred at 450 RPM using a $2 \mathrm{~mm}$ PTFE coated magnetic bar with a raised ring in the middle. The dissolved oxygen (DO) concentration was manually measured using the Hach HQ40d oxygen meter coupled with a Hach probe. DO was measured once per day until the substrate was completely used up. The second part of the aerobic batch tests was for the determination of the biokinetic parameters. The acclimated microorganisms were transferred to a $500 \mathrm{ml}$ open batch reactor that was placed on a single stirrer. $1 \mathrm{~g} / \mathrm{l}$ of the model compound was used with a bioreactor working volume of $250 \mathrm{ml}$. The stirring speed was the same as the acclimation phase but a $5 \mathrm{~mm}$ stirring bar was used. The DO meter was programmed to automatically and continuously record DO concentration data at specified time intervals i.e. every 15 minutes. The oxygen mass transfer coefficient $k_{L} a$ of the bioreactor was taken into account and measured as described by the procedure proposed by Benedek and Heideger [13] and adapted by Sheppard [14]. All aerobic experiments were conducted at room temperature $\left(22^{\circ} \mathrm{C}\right)$.

For experiments with nitrate as the electron acceptor, the same set-up for the acclimation experiments as described above was used but in this case, the bottles were sealed with Tetflon-coated butyl rubber stoppers and crimped. Nitrogen as nitrate $\left(\mathrm{NO}_{3}-\mathrm{N}\right)$ was measured once per day using the Spectroquant Nitrate test kit 1.14563.0001. 
For the anaerobic experiments, a water displacement set-up was used. A one-holed rubber stopper was used to seal the bottle with the tubing from the bottle connected to a gas collection cylindrical tube. The gas collection cylinder which was supported by a retort stand was filled with $1 \mathrm{M} \mathrm{KOH}$ and then inverted into a container of $1 \mathrm{M}$ $\mathrm{KOH}$ solution that was placed on a stirrer. The anoxic and anaerobic experiments were conducted at room temperature and $40^{\circ} \mathrm{C}$ using the soil inoculum and were deoxygenated by sparging with nitrogen gas for 20 minutes before use. Control experiments which contained mineral salts and inoculum but no substrate were also set up under all the conditions investigated.

GC measurements of n-alkanes. At the conclusion of the batch experiments, the remaining n-alkanes were extracted three times using hexane as the extraction solvent. The extraction of the n-alkanes in preparation for GC analysis was carried out by adapting the technique utilized by Poster [15]. The extraction efficiency in all cases was $94 \pm 3 \%$. Analyses of the extract were performed using GC Trace 1300 equipped with a flame ionization detector (FID) and a 30m x 0.25mm, TG-WaxMS capillary column. After an initial hold for $2.5 \mathrm{~min}$ at $90^{\circ} \mathrm{C}$, the temperature was programmed to increase at $10^{\circ} \mathrm{C} / \mathrm{min}$ to $300^{\circ} \mathrm{C}$ for $3 \mathrm{~min}$.

The volatile fatty acids (VFA) were also measured with the GC using the following settings. The initial temperature of the column was $80^{\circ} \mathrm{C}$ for 2 min followed with a ramp of $20^{\circ} \mathrm{C} / \mathrm{min}$ and a final temperature of $200^{\circ} \mathrm{C}$ for $1 \mathrm{~min}$; the injector and detector temperatures were $200^{\circ} \mathrm{C}$ and $250^{\circ} \mathrm{C}$ respectively. Hydrogen was used as the carrier gas at a flowrate of $35 \mathrm{ml} / \mathrm{min}$ for both n-alkanes and the VFA measurements.

Other measurements i.e. VSS and COD measurements were carried out according to the procedures described elsewhere [15,16,17].

\section{Determination of Kinetic Parameters}

\subsection{Model Description}

The concept of the mathematical formulation was based on COD mass balance where part of the carbon source is utilized by the microorganisms to produce more microorganism and the rest is oxidized using oxygen under aerobic conditions according to the equation below:

$$
\left(-\Delta S_{C O D}\right)=\Delta X_{C O D}+\left(-\Delta O_{2}\right)
$$

Where $-\Delta S_{C O D}$ is the substrate removed as COD $(\mathrm{kg}$ $\left.\mathrm{COD} / \mathrm{m}^{3}\right) . \Delta X_{C O D}$ is the microorganisms produced as COD $\left(\mathrm{kg} \mathrm{COD} / \mathrm{m}^{3}\right) .-\Delta O_{2}$ is the oxygen consumed $\left(\mathrm{kg} \mathrm{O}_{2} / \mathrm{m}^{3}\right)$. Eq. (1) can then be expressed in terms of rate as [18]:

$$
-r_{S C O D}=\left(r_{X}+r_{\text {end }}\right) 1.42-r_{O_{2}}
$$

Where, $r_{S C O D}$ is the rate of substrate consumption, $r_{x}$ is the rate of biomass growth, $r_{\text {end }}$ is the rate of endogenous metabolism and $r_{\mathrm{O} 2}$ is the rate of oxygen consumption.

The model is formulated from mass balances for biomass growth, substrate and oxygen consumption using the general mass balance for a batch reactor with a constant volume given as:
Accumulation $=$ generation - consumption.

The growth kinetics for biomass growth has been assumed to be first order with respect to biomass according to Eq. (3) [19,20,21].

$$
\frac{d X}{d t}\left(\frac{k g \text { biomass }}{m^{3} \text { day }}\right)=r_{X}+r_{\text {end }}
$$

where

$$
r_{X}=\mu X
$$

and

$$
r_{\text {end }}=-b X
$$

Where $X$ is designated as biomass $\left(\mathrm{kg} / \mathrm{m}^{3}\right)$, b is the endogenous biomass decay rate $\left(\mathrm{day}^{-1}\right)$ [22] and $\mu$ is the specific growth rate $\left(\right.$ day $\left.^{-1}\right)$. The specific growth rate $\mu$ was assumed not only limited by substrate but by oxygen and therefore a dual Monod kinetic equation [23,24,25] was used.

$$
\mu=\mu_{\max }\left(\frac{S}{K_{s}+S}\right)\left(\frac{O_{2}}{K_{O_{2}}+O_{2}}\right)
$$

Where $\mathrm{S}$ is the substrate concentration $\left(\mathrm{kg} \mathrm{COD} / \mathrm{m}^{3}\right), K_{s}$ is the half saturation constant for substrate consumption $\left(\mathrm{kg} \mathrm{COD} / \mathrm{m}^{3}\right)$ and $K_{\mathrm{O} 2}$ is the half saturation constant for oxygen consumption $\left(\mathrm{kg} / \mathrm{m}^{3}\right) . \mu_{\max }$ is the maximum specific growth rate $\left(\right.$ day $\left.^{-1}\right) . K_{O 2}$ was assumed in all cases to be equal to $0.0001 \mathrm{~kg} / \mathrm{m}^{3}$ [26].

\subsection{Biomass Balance}

Biomass concentration in the reactor is a function of biomass formed from substrate utilization and biomass consumed from endogenous metabolisms i.e.

\section{Biomass accumulated \\ = biomass generated - biomass consumed .}

Therefore, the rate of biomass accumulation is

$$
\begin{aligned}
& \frac{d X}{d t}\left(\frac{k g \text { biomass }}{m^{3} \text { day }}\right) \\
& =\mu_{\max }\left(\frac{S}{K_{s}+S}\right)\left(\frac{O_{2}}{K_{O_{2}}+O_{2}}\right) X-b\left(\frac{O_{2}}{K_{O_{2}}+O_{2}}\right) X .
\end{aligned}
$$

\subsection{Substrate Balance}

\section{Substrate accumulated \\ = substrate generated - substrate consumed.}

No substrate is generated in this case, the consumption of substrate was assumed to be a function of the concentration of the active microbial biomass [27]. Therefore, the rate of substrate accumulation is thus given as:

$$
\frac{d S}{d t}\left(\frac{k g C O D}{m^{3} \text { day }}\right)=-\frac{\mu_{\max }}{Y_{X / S}}\left(\frac{S}{K_{S}+S}\right)\left(\frac{O_{2}}{K_{O_{2}}+O_{2}}\right) X
$$


Where $Y_{X / S}$ is the biomass growth yield coefficient given as

$$
Y_{X / S}=\frac{k g \text { biomass } X}{k g \text { substrate } S}=\frac{r_{X}}{-r_{S}} \text {. }
$$

\subsection{Oxygen Balance}

\section{Oxygen accumulation \\ = oxygen in + oxygen generated - oxygen consumed .}

Oxygen entering the aqueous phase from the gas phase is consumed for biomass growth and endogenous metabolism, no oxygen is generated. The oxygen mass balance is thus given as:

$$
\begin{aligned}
& \frac{d O_{2}}{d t}\left(\frac{k g \text { oxygen }}{m^{3} \text { day }}\right) \\
& =-\frac{\mu_{\max } S}{K_{s}+S}\left(\frac{1}{Y_{X / S}}-1.42\right)\left(\frac{O_{2}}{K_{O_{2}}+O_{2}}\right) X \\
& -1.42 b\left(\frac{O_{2}}{K_{O_{2}}+O_{2}}\right) X+k_{l} a\left(C_{O_{2}}^{*}-C_{O_{2}}\right)
\end{aligned}
$$

Where $C_{O_{2}}^{*}$ is the saturation oxygen concentration $\left(\mathrm{kgO}_{2} / \mathrm{m}^{3}\right)$, measured in water at the temperature and pressure used in the experiments, and $C_{\mathrm{O}_{2}}$ is the concentration of oxygen under working conditions $\left(\mathrm{kgO}_{2} / \mathrm{m}^{3}\right)$.

\subsection{Numerical Implementation}

In this model, initial values of $\mathrm{S}_{0}$ measured as the COD, $\mathrm{X}_{\mathrm{o}}$ (which was the VSS measurement taken before the addition of the substrates) \& $C_{O 2 o}$ are given and optimal values of biokinetic parameters were determined by nonlinear regression of the oxygen concentration data obtained from the batch experiments. Eqs (7), (8) \& (10) were solved simultaneously for known values of initial estimates of the kinetic parameters using a nonlinear fitting process in Microsoft Excel that would give the best fit of the kinetic model to the experimental data. The output values from the solution are $\mathrm{S}, \mathrm{X}$ \& dissolved oxygen data as a function of time. The model has four adjustable parameters $\left(\mu_{\max }, K_{s}, b, Y_{(X / S)}\right)$ and the nature of the non-linear equations required using a very small time step i.e. $\Delta t=0.0001$ day. The parameters were optimized by minimizing the sum of squared deviation (SSD) as shown in Eq.(11) between the experimental data of the batch test and the simulated data using the Solver program (GRG nonlinear Algorithm) incorporated in Microsoft Excel package.

$$
S S D=\left(U_{e}-U_{S}\right)^{2}
$$

Where $\mathrm{U}_{\mathrm{e}}=$ experimental $\mathrm{DO}$ concentration, $\mathrm{U}_{\mathrm{s}}$ =simulated DO concentration

\section{Results and Discussion}

\subsection{Aerobic Conditions}

The DO profiles for the readily biodegradable substrates and n-alkanes during the acclimation phase are shown in Figure 1. The readily biodegradable substrates were chosen to enable adequate comparison with the degradation rate of the n-alkanes used for this research. As shown in the DO profiles, the dissolved oxygen concentration begins to drop as the microorganisms acclimate to the substrates and once the substrate was used up, the DO concentration began to rise until it reached a value close to the saturation level. The results obtained showed that the AD sludge inoculum showed the same fast acclimation and substrate removal rate as the soil inoculum even though the conditions preceding its usage in our experiments were completely anaerobic. This indicates that the microbial community present in the anaerobic sludge can easily adjust to an aerobic environment and carry out their metabolic functions effectively. The results of the control bioreactors showed no decrease in DO concentration during the course of the experiments (results not shown). This means that the decrease in DO concentration was as a result of the microbial metabolic activity on the substrates added and not due to microbial endogenous metabolism or the consumption of other carbon sources that might have been present in soil inoculum or AD digester. Indeed, for the nalkanes (C12, C14 \& C16) the GC analysis conducted at the end of the test, after the DO concentrations increased to a stable value, showed that the substrates were completely removed (data not shown).

The profiles of soluble COD were measured during the tests with glucose and with C12 to determine whether biodegradation of hydrocarbons involves the release of soluble compounds into the water phase. Indeed, the metabolic pathway of n-alkane biodegradation under aerobic conditions proceeds through the conversion of nalkanes to alcohol to aldehyde to carboxylic acids before the subsequent mineralization to $\mathrm{CO}_{2}$ and water [28]. Therefore, it is possible that these metabolic intermediates are released from the cells during the biodegradation of the hydrocarbons. As expected, in the glucose reactor, the COD concentration decreased as the DO concentration decreased (Figure 2a) and no further decrease in COD was observed when the DO concentration started to rise. For $\mathrm{C} 12$, no change of the concentration of soluble COD was observed during the biodegradation of this substrate (Figure 2b) and this indicates, that either metabolic intermediates were not released during the biodegradation for $\mathrm{C} 12$, or they were released but consumed very shortly after their release into the medium.

The investigation of the biodegradation of organic substrates through respirometry (i.e. oxygen consumption) has shown that the approach is a good indicator for determining biodegradation. Previous studies have reported high degree of biodegradation of n-alkane fractions under aerobic conditions in very different experimental systems. A study by Olsen et al conducted with batch flasks experiments showed that $75 \%$ of the nalkane fraction of diesel oil was biodegraded in 35 days [29]. Lal and Khanna observed about 18-43\% degradation of n-alkane fraction of different sources of crude oil over 15 days using pure cultures of Acinetobacter calcoaceticus and Alcaligenes odorans [30]. Setti et al reported that the degradation of lower molecular weight alkanes was more significant than higher chain length and that the decrease in percentage biodegradation with 
increase in chain length was more significant for C12-C16 [31]. In this study we observed complete biodegradation of C12, C14 and C16 and incomplete biodegradation for C18 and C20. The reason for incomplete biodegradation of C18 and C20, at least in the time length of our experiments, is not clear. However, it is important to observe that, although all the n-alkanes considered in this study are virtually insoluble in water, C12, C14 and C14 are liquid at room temperature while C18 and C20 are solid. There are different mechanisms by which microorganisms utilize organic substrates present at concentrations that exceed their water solubility [32]. The biodegradation rate of hydrocarbons can be affected by its physical state. Liquid hydrocarbons are usually metabolized by being incorporated into the microbial cell membrane [33] whereas the mechanism by which solid hydrocarbons are utilized still remains open for debate. The microbial utilization of insoluble solid hydrocarbons is difficult because of the amount of energy that is required to disperse the solids [34]. In essence, in a system where insoluble substrates are present, the microorganisms are expected to first utilize the portion of the substrates in solution and the subsequent rate of uptake of the substrates will be limited by the rate of dissolution [35].
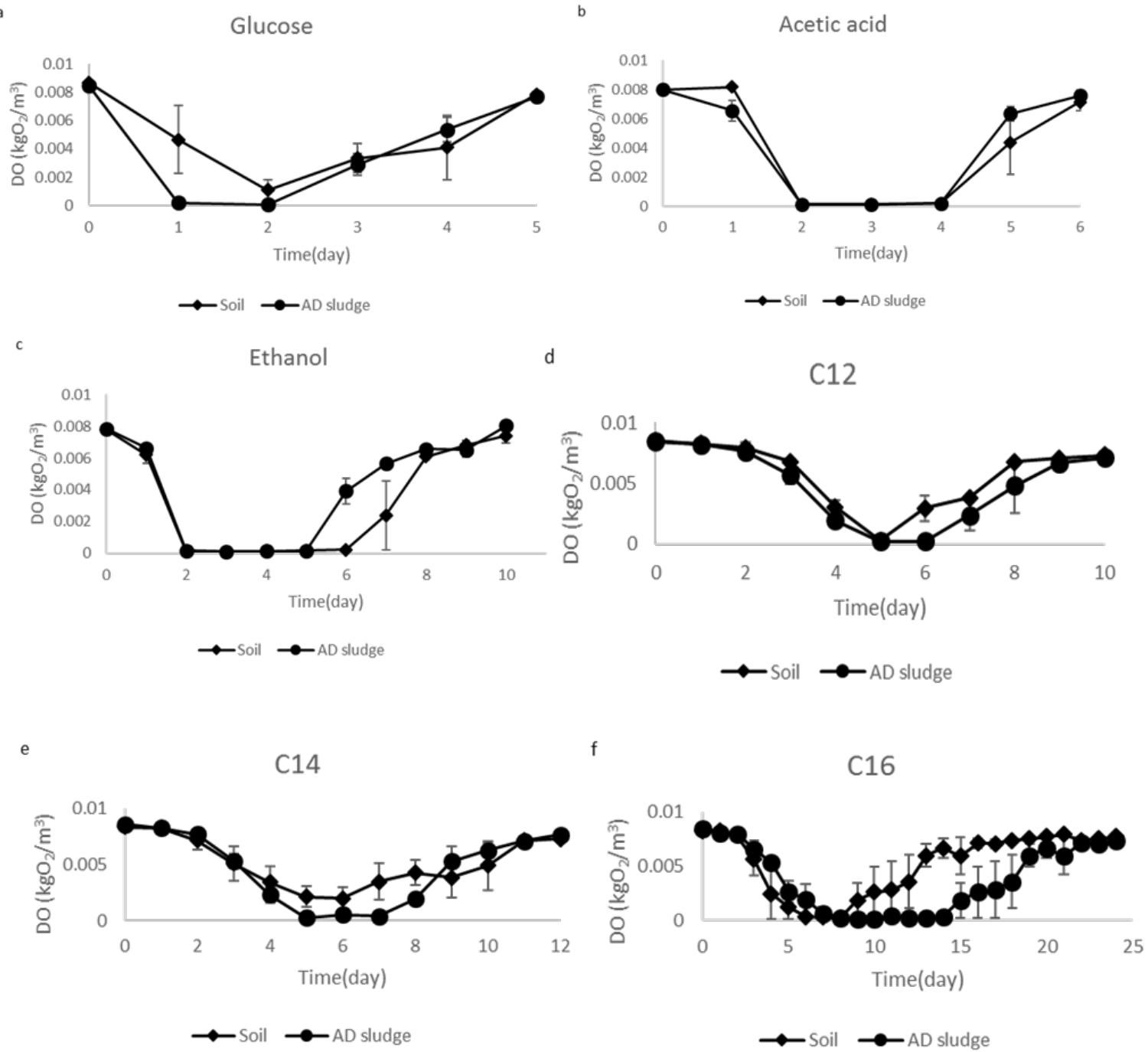

C18

$\mathrm{h}$

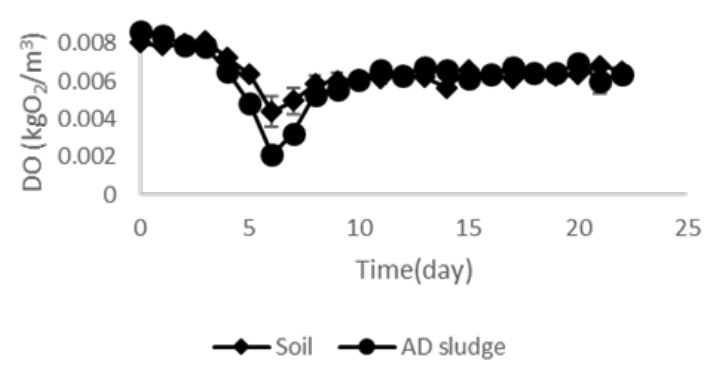

Figure 1. (a)- (h), DO concentration profiles for the various substrates. Standard error calculated for three replicates. Experiments were carried out with an initial concentration of $0.5 \mathrm{~g} / \mathrm{l}$ of each substrate 

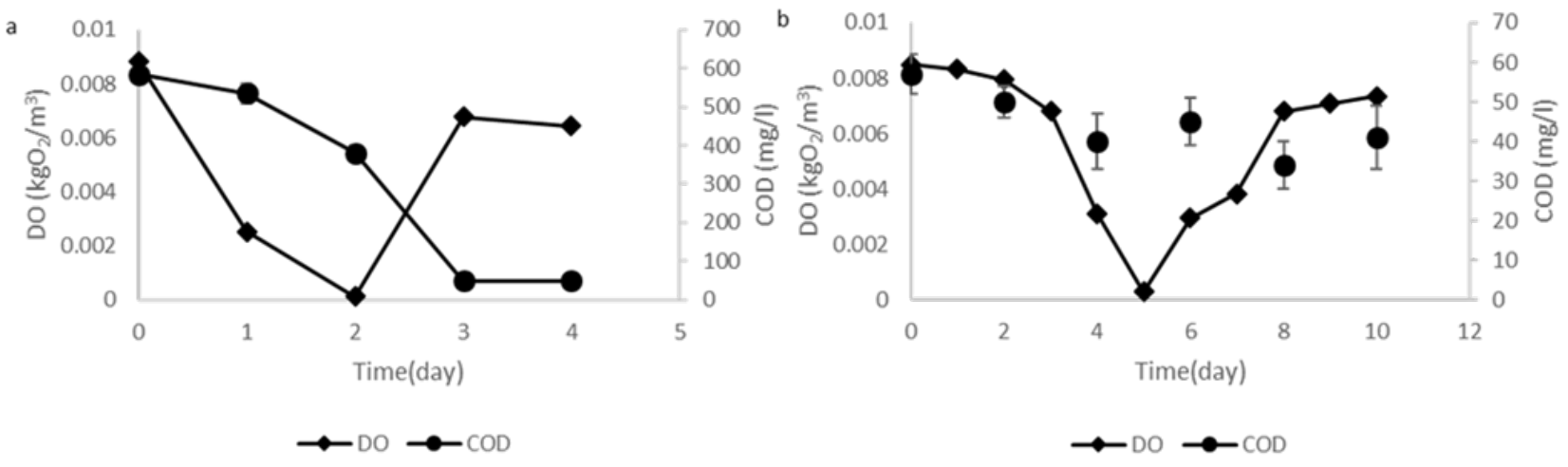

Figure 2. DO and COD measurements taken during the acclimation for a) glucose and b) C12

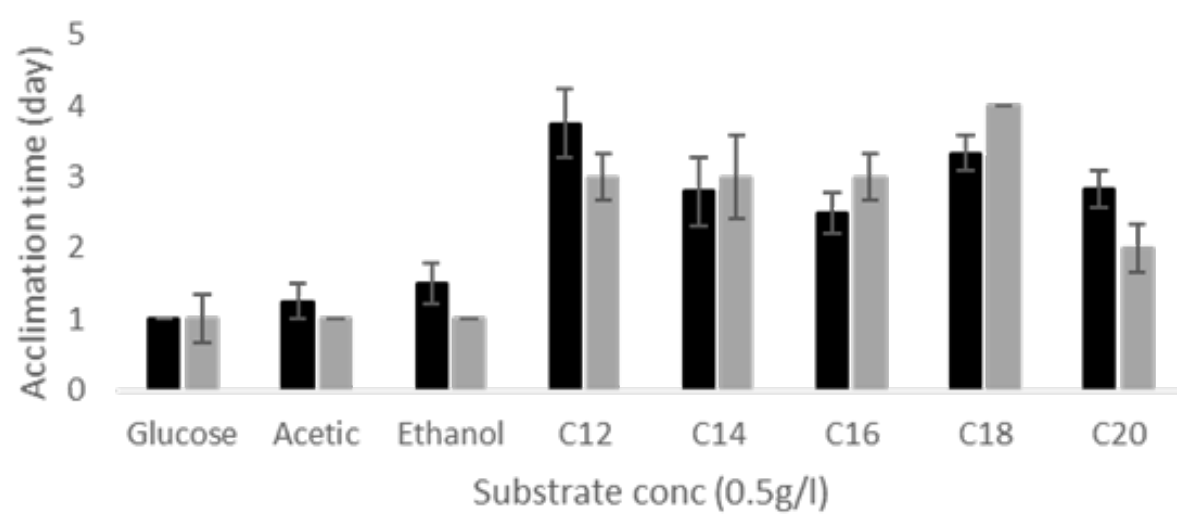

a Soil

Figure 3. Effect of inoculum type on acclimation time. Results are for experiments at room temperature under aerobic conditions. Standard errors calculated for at least three replicates

\subsection{Acclimation Time}

Microorganisms usually require time to adjust to certain conditions when placed in a new environment. Acclimation is normally preceded by a lag time after which significant growth of the microorganisms can occur. A criterion to determine the acclimation time under aerobic conditions was arbitrarily defined. i.e. acclimation was set to have occurred when the DO concentration decreased by $10 \%$ with respect to the initial value. Figure 3 shows the effect of the nature of the substrate and of the inoculum type on the acclimation time. The acclimation time for hydrocarbons was longer than the readily biodegradable substrates. Indeed, the acclimation time for the readily biodegradable substrates was in general between 1-2 days while for the hydrocarbons it was between 3-5 days. It is important to observe that the acclimation time was approximately the same for all the readily biodegradable substrates and it was also very similar for all the hydrocarbons. This means that the microorganisms were able to acclimate to glucose, ethanol and acetic acid with the same rate and, similarly, they exhibited the same behaviour with the hydrocarbons considered here. The reason for the longer acclimation period with the n-alkanes than with the readily biodegradable substrates can be explained considering that acclimation is affected by the chemical nature of organic substrates, their physical state and the concentration in which they are present. n-Alkanes are insoluble in water unlike the readily biodegradable substrates and as result may not be initially available to the microorganisms in the aqueous phase. Their metabolism would therefore depend on their availability to the microorganisms in the aqueous phase which is usually achieved by the production a solubilising agent like biosurfactant to aid their uptake $[36,37,38]$. This period of producing biosurfactant may be responsible for the longer acclimation time observed for the n-alkanes. In general, the acclimation time for the nalkanes was longer than the readily biodegradable substrates but was still relatively short considering the fact that the microbial community present in the two sources of inoculum used was not previously exposed to these hydrocarbon compounds. Figure 3 also shows that there was no significant difference in acclimation time for the two sources of inoculum. This indicates that, for open mixed cultures, the nature of the substrate is more important in determining the acclimation time than the type of mixed culture, at least for the mixed cultures considered in this study. Experiments were also conducted to determine the effect of initial substrate concentration on acclimation time over a range of concentrations. The results show that acclimation is independent of the initial substrate concentration for both the readily degradable substrates and the n-alkanes (data not shown). This shows that the mixed cultures considered in this study were not inhibited by higher concentrations of any of these substrates. This result is an important evidence that indicates the feasibility of biological treatment with open mixed cultures even for sites or wastewater with relatively high concentration of hydrocarbons. 


\subsection{Anoxic Condition}

Figure 4 shows the experimental results of nitrate concentration profile over time using glucose conducted at room temperature and $40^{\circ} \mathrm{C}$. After an initial acclimation phase i.e. approximately 2 days at room temperature and under 1 day at $40^{\circ} \mathrm{C}$, the utilization of nitrate and glucose began simultaneously resulting in the decrease in the concentration of nitrate in bioreactors. This decrease in nitrate concentration stopped once there was no glucose available in the bioreactors as indicated by the COD measurements.

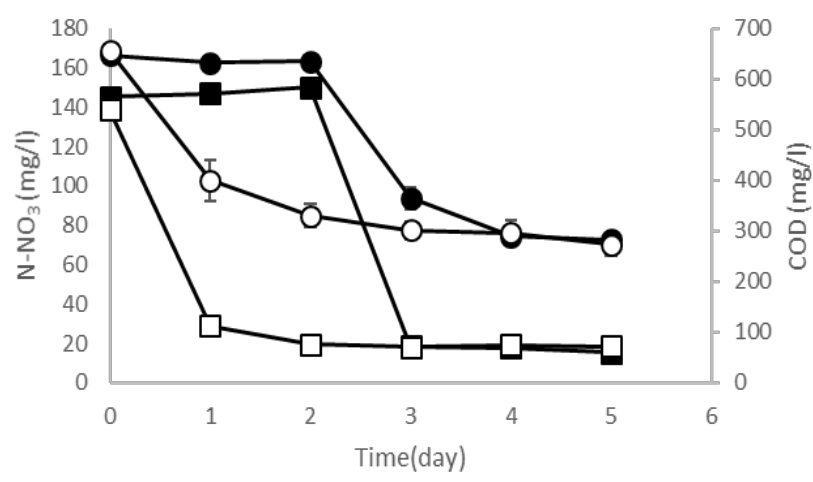

$\rightarrow$ Nitrate $(22 \mathrm{C}) \rightarrow \mathbf{- N i t r a t e}(40 \mathrm{C}) \rightarrow \operatorname{COD}(22 \mathrm{C}) \rightarrow \square-\mathrm{COD}(40 \mathrm{C})$

Figure 4. Nitrate and COD consumption measurements in bioreactors with glucose at room temperature and $40^{\circ} \mathrm{C}$. Standard error calculated for at least 3 replicates

These batch experiments indicate that the mixed cultures were able to use nitrate as electron acceptor when growing on glucose. Figure 5 shows the nitrate consumption profiles for the hydrocarbons at room temperature and $40^{\circ} \mathrm{C}$. A modest decrease in nitrate concentration was observed at room temperature (Figure 5a) and the consumption of nitrate started between 20-25 days after starting the experiments. The GC analysis conducted at the end of the experimental period with C12, C14 and C16 bioreactors showed that approximately $76-80 \%$ of these compounds were still present in the bottles. This means that even though nitrate concentration decreased, utilization of n-alkanes by microorganisms under these conditions proceeded at a very slow rate. The overall rate of removal of the hydrocarbons under anoxic conditions was much lower than under aerobic conditions. For the same conditions of temperature and hydrocarbon concentration a comparison of Figure 1 and Figure 5a shows that the hydrocarbons were completely removed within 20 days from inoculation under aerobic conditions while they were only partially removed after 40 days under anoxic conditions. At $40^{\circ} \mathrm{C}$ (Figure 5b), a significant consumption of nitrate was observed and nitrate was almost completely utilized in C12, C14 and C20 bottles. GC analysis conducted at the end of the experiments showed approximately $96-98 \%$ of C12 and C14 was removed, while for C16 about $46 \%$ of initial concentration was present. The GC analysis corresponded well with the nitrate concentration profiles in Figure 5b, and the high residual concentration of $\mathrm{C} 16$ at the end of the test corresponded with the lower amount of nitrate removed with this hydrocarbon. The control experiments showed no decrease in nitrate concentration (results not shown) confirming that the decrease in nitrate concentration in the anoxic experiments was due to the consumption of the test compounds by the mixed microbial culture used.

Figure 6 shows the experiments conducted with the mixed cultures at the end of their acclimation period with n-alkanes under anoxic conditions. One of the triplicate bottles of $\mathrm{C} 12$ and $\mathrm{C} 20$ at $40^{\circ} \mathrm{C}$ were spiked with $1 \mathrm{~g} / \mathrm{l}$ $\mathrm{NaNO}_{3}\left(168 \mathrm{mg} / \mathrm{l} \mathrm{N}-\mathrm{NO}_{3}\right)$ and $0.5 \mathrm{~g} / \mathrm{l}$ of the substrates. It can be seen from the results that nitrate was consumed at a much faster rate than in the acclimation experiments. The results obtained from these tests further prove the biodegradation of n-alkanes using nitrate and that the biodegradation process can be faster with prior exposure of the microorganisms to the substrates.

From the results obtained, n-alkanes can be metabolized by microorganisms using nitrate as the terminal electron acceptor. It should be noted that ammonium $\left(\mathrm{NH}_{4} \mathrm{Cl}\right)$ was present in significant amount in the culture media to ensure that the nitrate added was only used for respiration and not as a nitrogen source for microbial cell synthesis. Higher nitrate consumption was observed in the bottles amended with hydrocarbons when the temperature was increased to $40^{\circ} \mathrm{C}$. This is not surprising as the degradation of organic compounds increases with increasing temperature and microbial activities usually doubles for every $10^{\circ} \mathrm{C}$ increase in temperature [39]. Although nitrate consumption in the bioreactors amended with the n-alkanes was observed to be similar at onset of the experiments, it ceased in C16 bioreactors and significantly slowed down in the C18 bioreactors after 28 days (Figure 6b). The denitrification process involves a sequential reduction of nitrate to nitrite, nitric oxide, nitrous oxide and finally to dinitrogen gas [40]. The reduction of nitrate is activated by nitrate reductase enzyme and the nitrite formed from nitrate reduction induces the activities of nitrite reductases. Before the synthesis of the nitrite reductases, a transient accumulation of nitrite in the system might occur. Nitrite has been shown to be highly toxic to microbial cells and might hinder cell metabolic activities or even cause microbial cell decay [41]. It is possible that the enrichment cultures amended with C16 \& C18 had some nitrite accumulation, hence the low nitrate consumption, however nitrite was not analysed in this study, therefore further investigation is required to understand the reason for the lower nitrate reduction observed with $\mathrm{C} 16$ and $\mathrm{C} 18$. In the literature, there is some evidence of anoxic biodegradation of nalkanes, however this is mostly limited to pure cultures and to C16 [42,43], while there is little or no investigation of open mixed cultures in the anoxic biodegradation of these substances.

Figure 7 compares the acclimation times under anoxic and aerobic conditions. For glucose, the acclimation time was very similar for the two electron acceptors. For the nalkanes, however, the acclimation time under anoxic conditions was much longer than under aerobic conditions. Indeed, the acclimation time for the hydrocarbons was 2025 days under anoxic conditions vs 3-5 days under aerobic conditions. In essence, the results obtained from this study show that the mixed culture acclimate much faster to nalkanes under aerobic conditions which means using nitrate as the electron acceptor in subsurface bioremediation will take a longer time to achieve the set objective than when 
oxygen is introduced or injected. It should be noted however that a criterion to determine the acclimation time under anoxic conditions was also arbitrarily defined i.e. when about $10 \%$ of the initial nitrate concentration was consumed.
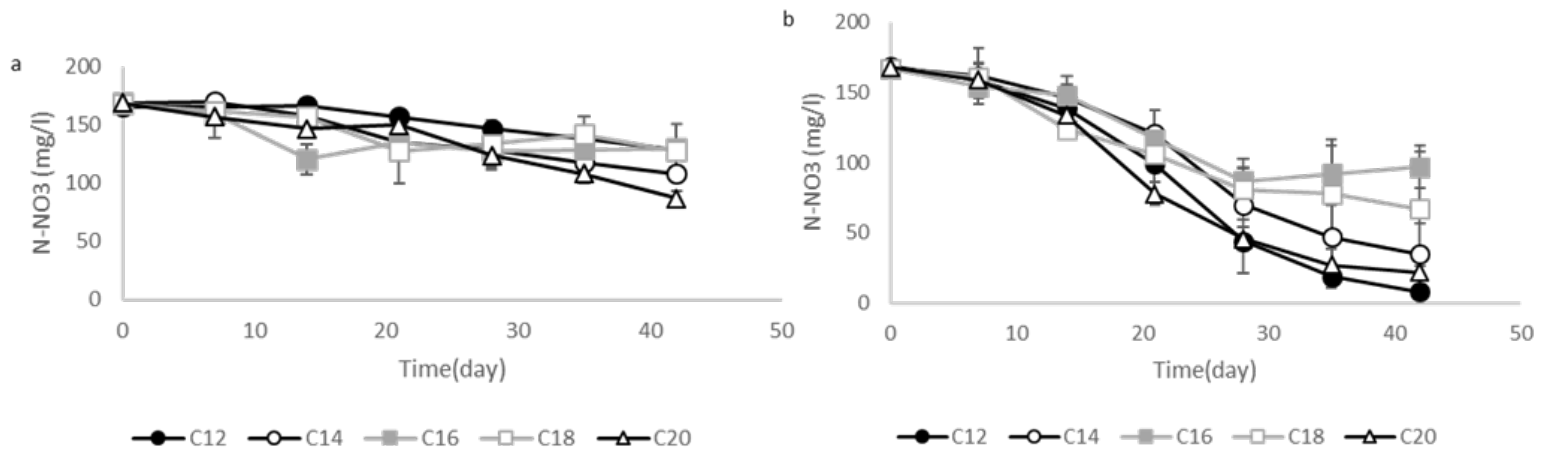

Figure 5. Nitrate consumption measurement for experiments conducted with n-alkanes. a) at room temperature, b) at $40^{\circ} \mathrm{C}$. Standard error calculated for three replicates
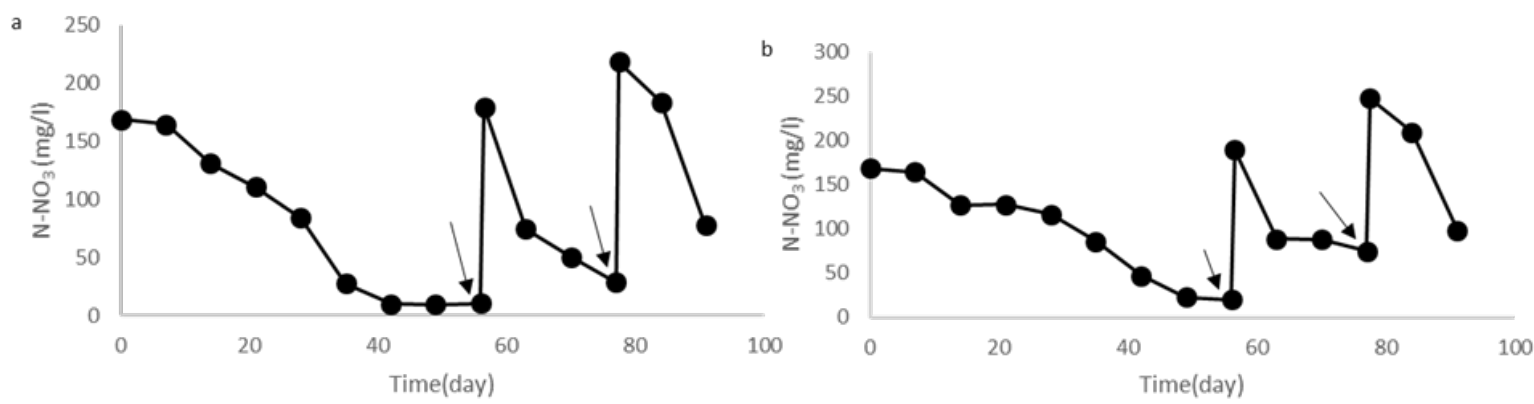

Figure 6. Spike with one of the a) C12 \& b) C20 batch reactors to further investigate nitrate consumption. Arrows indicate the spike of substrate and nitrate

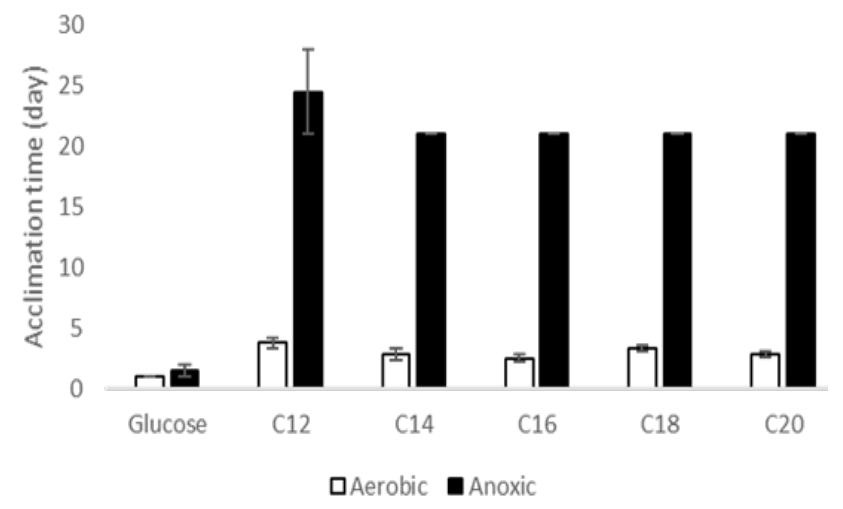

Figure 7. Comparison of acclimation times between aerobic and anoxic conditions. Results are for experiments with soil inoculum at room temperature

\subsection{Anaerobic Conditions}

The results of the anaerobic experiments, in the absence of any external electron acceptors, conducted at room temperature and $40^{\circ} \mathrm{C}$ are shown in Figure 8. For the glucose-amended reactors, there was a lag phase of 3-6 days after which the volume of liquid displaced corresponding to the amount of gas produced increased sharply and then ceased afterwards. For the n-alkanes, no gas production was observed throughout the experiments under the two temperature conditions. VFAs were measured at the end of the tests and it was found that acetic acid accumulated in the glucose reactors at concentrations in the range 200-250 mgCOD/l, while no accumulation of VFAs was observed for the hydrocarbon-fed reactors. These results indicate therefore that under anaerobic conditions the mixed cultures used in this study were able to metabolise glucose but not any of the hydrocarbons.

For the glucose reactor, higher gas production was observed at $40^{\circ} \mathrm{C}(140 \mathrm{ml})$ than at $22^{\circ} \mathrm{C}(50 \mathrm{ml})$. Since the glucose concentration at the start of the test was the same in both tests, the lower volume of gas production at the lower temperature is an indication of higher inhibition of microbial metabolism under these conditions. However, inhibition was observed in the glucose reactors at both temperatures. Indeed, at both temperatures no increase in gas production was observed when glucose was spiked again, as indicated by the arrows in Figure 9. Some anaerobic digestion studies have shown that the presence of some VFA in the concentration range of 30-60 mg/l, lower than the ones observed in this study in the glucose reactors, inhibited growth [44]. The higher inhibition observed at lower temperature in our study is not surprising, because it is known that anaerobic digestion processes are sensitive to many variables including $\mathrm{pH}$, temperature, volatile fatty acid (VFA) and nutrients availability.

Our experiments have shown that the mixed cultures used in this study were not able to use hydrocarbons under anaerobic conditions, even after an acclimation time of 150 days. There is some limited literature evidence that hydrocarbons are biodegradable under anaerobic conditions, albeit very slowly $[45,46]$. These studies used mixed cultures of pure microbial strains isolated from oilfields and other hydrocarbon contaminated sites. However, to the best of our knowledge, there is no reported investigation on the anaerobic biodegradation of n-alkanes using open mixed microbial cultures. In our study, we used soil inoculum obtained from an agricultural site which had no prior exposure to hydrocarbon substrate. It 
is possible our experimental period was not long enough for any significant biological degradation of the n-alkanes under anaerobic conditions to occur. Our study involved the use of unacclimated mixed culture from a non-hydrocarbon contaminated site of which microbial species capable of utilizing hydrocarbons particularly nalkanes as the substrates under these conditions might be missing in the mixed culture.
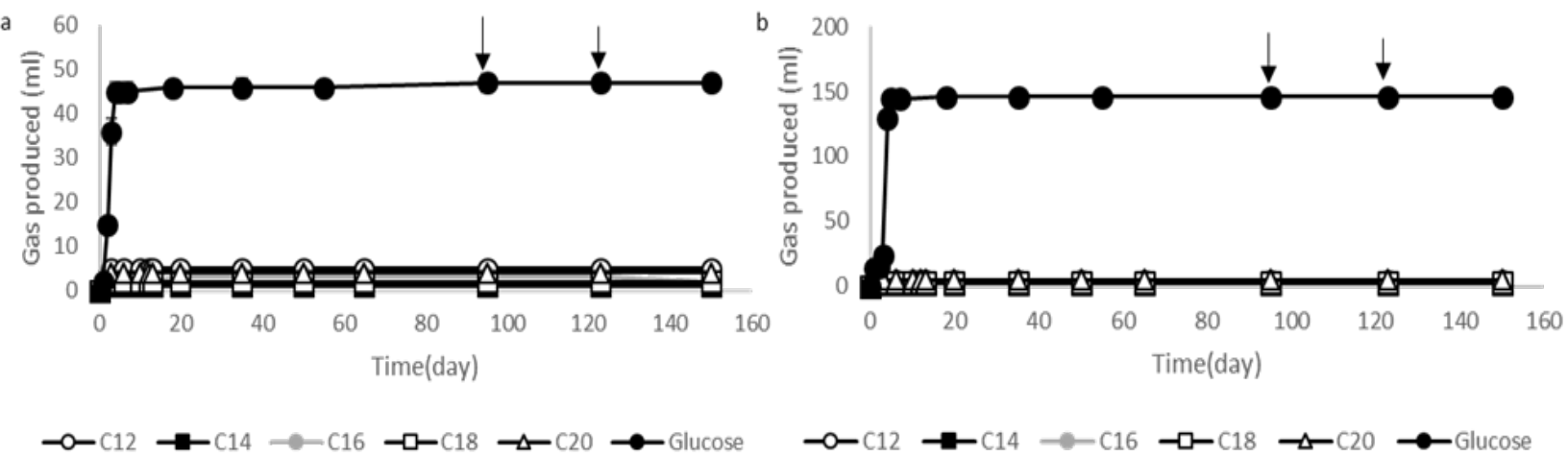

Figure 8. Gas produced over time at a) room temperature and b) $40^{\circ} \mathrm{C}$. The small volume of gas produced in the control experiments (without substrate) was subtracted from all the data points. Arrows indicate the time when additional spikes of substrate were carried out.

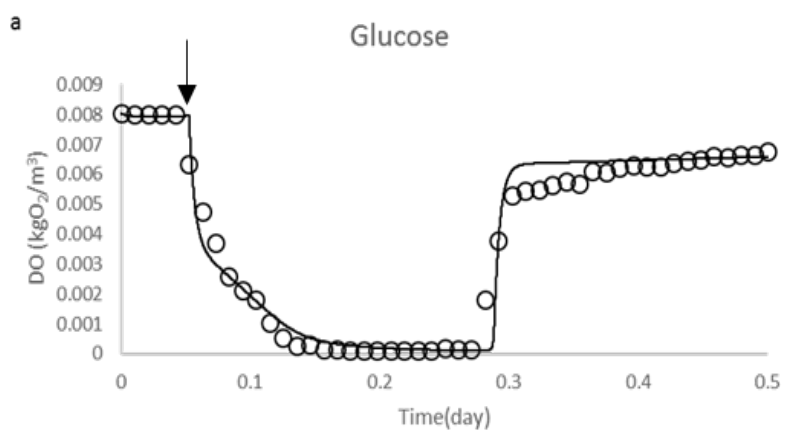

- Experiment -Model

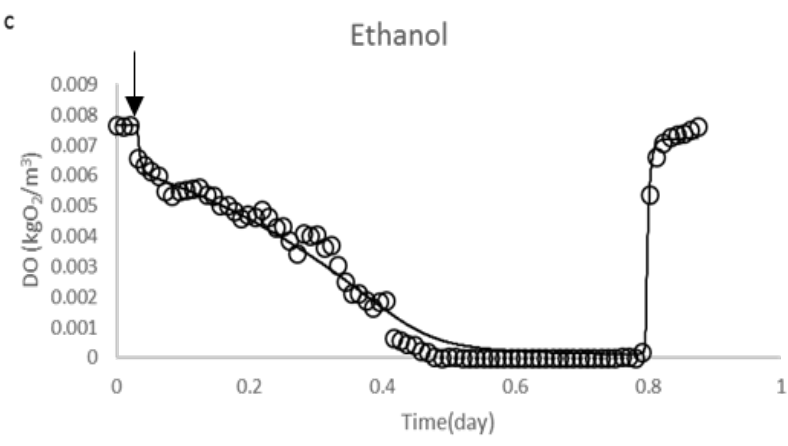

○ Experiment - Model

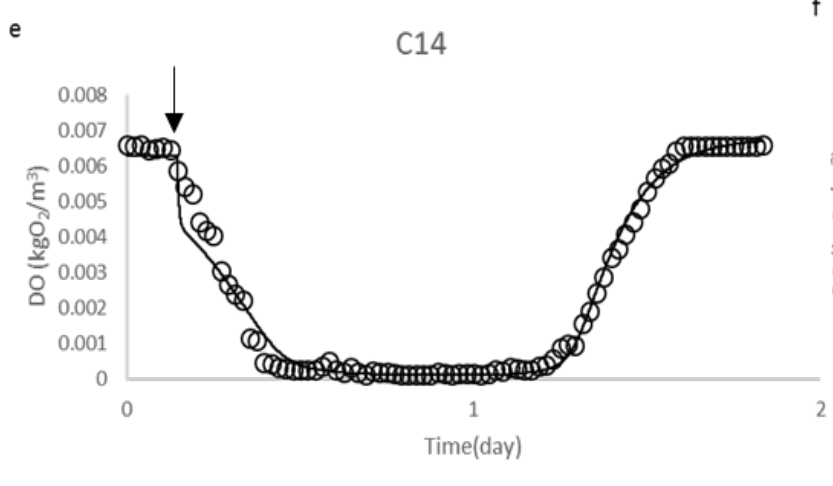

○ Experiment - Model

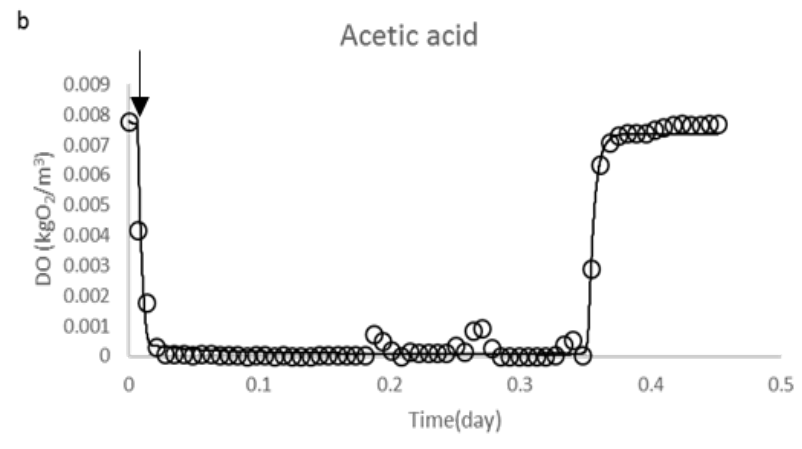

- Experiment - Model

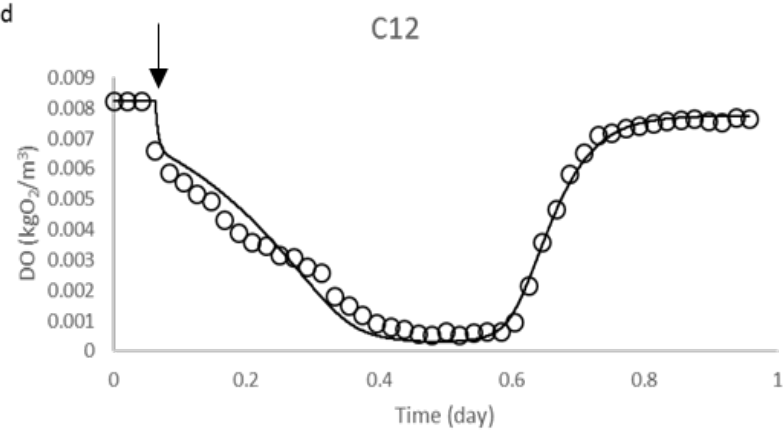

- Model 0 Experiment

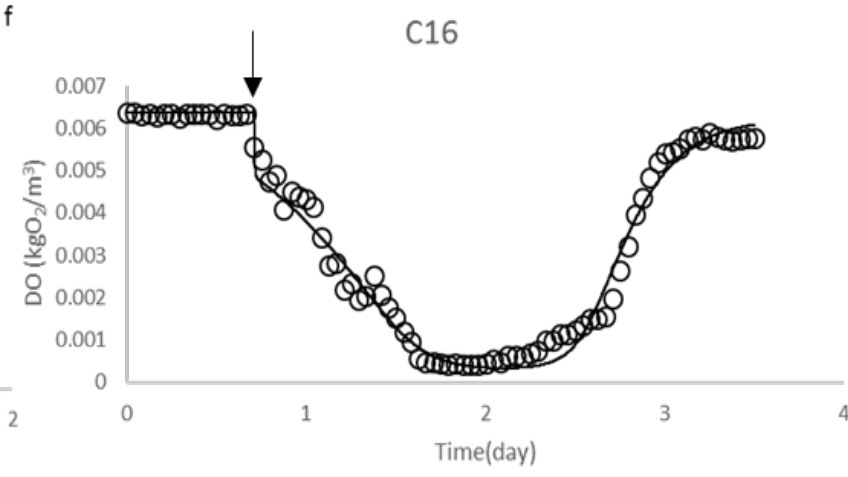

○ Experiment - Model

Figure 9. (a)-(f). Experimental data and model fit of the various substrates. Arrows indicate the time of substrate spike. 


\subsection{Model Result}

Figure 9 shows the results of the kinetic experiments carried out with glucose, acetic acid, ethanol, C12, C14 and $\mathrm{C} 16$ at the end of the acclimation phase. Kinetic experiments were also carried out with C18 and C20 at the end of the acclimation phase, when the DO concentration was the highest, but for these substrates we observed no drop in DO following the substrate spike (data not shown). For all the substrates except C18 and C20 the DO dropped immediately after the spike of the substrate. This indicates that, once microorganisms are acclimated on a substrate, they are immediately able to remove it without any lag phase. The use of respirometric data for parameter estimation requires that the microorganisms are fully acclimated to the substrate.

The fitting of the Monod model to the experimental data is always very good. The values of the fitted parameters are reported in Table 1, while Table 2 reports literature values of these parameters. For readily biodegradable substrates, microorganisms showed the highest $\mu_{\max }$ value for glucose, while the maximum growth rate on ethanol was the lowest. Most of the data reported in literature about the maximum specific growth rate $\mu_{\max }$ were on experiments utilizing pure strains. The obtained $\mu_{\max }$ in this study using open mixed culture are comparable to literature values. The obtained values for the endogenous decay rate constant $b$ were fairly reasonable as well and within the reported range of literature values. The biomass yield coefficient obtained by the model are within range of values reported for most organic substrates i.e. 0.2 to $0.67 \mathrm{~kg}$ biomass/ $\mathrm{kg}$ COD [23]. The value of the half saturation constant $K_{s}$ is difficult to determine and most values reported in literature for readily biodegradable substrate is usually very low because during most of the respirometric test, $S>>K_{s}$. The obtained $K_{s}$ values for the readily biodegradable substrates in this study are very similar to the literature values reported in Table 2.

For n-alkanes, the values of the parameters $\mu_{\max }, b$ and $\mathrm{Y}_{\mathrm{X} / \mathrm{S}}$ are within the same range as for the readily biodegradable substrates glucose, acetic acid and ethanol. However, an important difference is the value of the parameter $K_{s}$, which is much larger for the hydrocarbons (0.4-0.9 $\mathrm{kg} \mathrm{COD} / \mathrm{m}^{3}$ ) than for the readily biodegradable substrates $\left(0.004-0.008 \mathrm{~kg} \mathrm{COD} / \mathrm{m}^{3}\right)$. The larger value of the $K_{s}$ for the hydrocarbon is the mathematical consequence of the much slower increase of DO observed for the hydrocarbons than for the readily biodegradable substrates. Indeed, Figure 9 shows that for acetate, glucose and ethanol the DO profile shows a very sharp increase towards the end of the test, while the increase in DO for the hydrocarbons is much slower. Mathematically, using the Monod model as we did in this study, this corresponds to a larger value of $K_{s}$ for the hydrocarbons. While the biological meaning of $\mu_{\max }$ is pretty straightforward, the interpretation of $K_{s}$ is less obvious. The half saturation constant is described to be closely related to the transport mechanism of a substrate across the microbial cell membrane. This means $K_{s}$ is dependent on the properties of the cell membrane and intracellular conditions, on the type of transporter proteins in the cell and also on the substrate properties. In addition to this, the $K_{s}$ for hydrocarbons and insoluble compounds may also be affected by the interfacial area between the microorganisms and hydrocarbons, the dissolution rate and the production of extracellular products that enhance bioavailability [47]. These considerations give an interpretation of $K_{s}$ as a reflection of the affinity of microbial cells to a substrate. Poor affinity for substrates is indicated by large $K_{s}$ values meaning low substrate availability while a low $K_{s}$ value indicates high substrate affinity. The larger value obtained is not surprising because hydrocarbons are not soluble in water and therefore they are much less accessible to microorganisms than soluble substrates such as acetic acid, glucose and ethanol. Even though it is not possible to associate the value of $K_{s}$ with any single physical property, the $K_{s}$ estimated in this study can still be useful in biodegradation models for groundwater and subsurface systems where there is a high degree of heterogeneity and as such many of the physical factors affecting $K_{s}$ cannot be directly measured.

Table 1. Kinetic parameters obtained in this study

\begin{tabular}{|c|c|c|c|c|c|}
\hline Substrates & $\mu_{\max }\left(\right.$ day $\left.^{-1}\right)$ & $\mathrm{K}_{\mathrm{s}}\left(\mathrm{kgCOD} / \mathrm{m}^{3}\right)$ & b $\left(\right.$ day $\left.^{-1}\right)$ & $Y_{\mathrm{X} / \mathrm{s}}$ (kgbiomass/kgCOD) & SSD $\times 10^{-5}$ \\
\hline Glucose & 7.7 & 0.004 & 0.57 & 0.46 & 1.47 \\
\hline Acetic acid & 6.4 & 0.008 & 0.19 & 0.31 & 1.03 \\
\hline Ethanol & 3.3 & 0.004 & 0.3 & 0.36 & 1.7 \\
\hline C12 & 6.4 & 0.4 & 0.07 & 0.59 & 2.5 \\
\hline C14 & 6.7 & 0.5 & 0.19 & 0.35 & 8.9 \\
\hline C16 & 2.7 & 0.9 & 0.14 & 0.21 & 9.9 \\
\hline
\end{tabular}

Table 2. Typical kinetic parameters reported in literature. $\mathrm{RBS}$ = readily biodegradable substrates

\begin{tabular}{|c|c|c|c|c|c|c|}
\hline Substrates & $\mu_{\max }\left(\right.$ day $\left.^{-1}\right)$ & $K_{s}\left(\mathrm{~kg} / \mathrm{m}^{3}\right)$ & b $\left(\right.$ day $\left.^{-1}\right)$ & $Y_{\mathrm{X} / \mathrm{s}}$ (kg biomass/kg COD) & Type of culture & Reference \\
\hline \multirow{3}{*}{ Glucose } & 6.79 & 0.0025 & n.d. & 0.51 & Saccharomyces cerevisiae & [52] \\
\hline & 10.08 & 0.004 & n.d. & 0.68 & Saccharomyces cerevisiae & [53] \\
\hline & 7.4 & 0.0016 & n.d. & 0.3 & Saccharomyces cerevisiae & {$[54]$} \\
\hline RBS & 6 & 0.004 & 0.2 & 0.3 & Mixed culture from activated sludge & [55] \\
\hline n-C23-C40 & 7.6 & n.d. & 0.76 & n.d & \multirow{2}{*}{ Mixed culture of hydrocarbon degrading microbes } & {$[6]$} \\
\hline BTEX & 6.4 & n.d. & 0.74 & n.d. & & {$[6]$} \\
\hline BTEX & $0.05-2.15$ & n.d. & n.d. & n.d. & Undefined mixed culture & [25] \\
\hline n-C17 & 1.57 & 0.88 & 0.01 & 0.6 & Undefined mixed culture & {$[56]$} \\
\hline n-C21 & 14.4 & 0.086 & n.d. & n.d. & Pure strain & {$[57]$} \\
\hline PAH & $0.9-11.2$ & n.d. & n.d. & 0.5 & Mixed culture of Pseudomonas strains & [58] \\
\hline
\end{tabular}


Comparing the kinetic parameters of C12, C14 and C16, we note that $\mathrm{C} 12$ and $\mathrm{C} 14$ were removed at similar rates (similar values of $\mu_{\max }$ and $K_{s}$ ), while C16 was removed at slower rate (lower value of $\mu_{\max }$ and higher value of $K_{s}$ ). Table 2 shows that there is very limited information on kinetic parameters for hydrocarbons in the literature. To the best of our knowledge, no studies on open mixed culture have been reported on the kinetic parameters for the hydrocarbons considered in this study. Geng et al. (2013) obtained for n-C17 kinetic parameters in a similar range to the ones we found in this study. In general, the $\mu_{\max }$ estimated in this study are within the range of values reported by previous studies for microorganisms growing on normal hydrocarbons. As far as the effect of the chain length of the n-alkanes on the biodegradation rate is concerned, no clear trend is observed in the literature. Some studies showed the degradation rates of $n$-alkanes decreases with increasing carbon chain length $[48,49]$. In contrast, studies undertaken by Walker and Colwell found no correlation of the biodegradation rates on carbon chain length for a synthetic mixtures of $n$-C10-C29 all of which were present in equal proportions [50]. As discussed above, in this study C16 stimulated the activities of the microorganisms to the least extent, while the maximum specific growth rate obtained for C12 and C14 was approximately the same. The endogenous decay rate constant $b$ for the hydrocarbons seems to be in a similar range as the values, i.e. 0.03-1.6 day $^{-1}$, obtained with cultures growing on readily biodegradable substrates $[6,51]$. The biomass yield coefficient obtained by the model seems comparable with previous studies on readily biodegradable substrates and other hydrocarbons as shown in Table 1.

Overall, this modelling study shows the possibility of obtaining the kinetic parameters of the Monod model for hydrocarbons using respirometric experiments.

\section{Conclusions}

This study has shown that n-alkanes are biodegradable by open mixed microbial cultures under aerobic and anoxic conditions but not, at least under the conditions investigated here, under anaerobic conditions. The acclimation time of the microorganisms to the hydrocarbons is longer than to readily biodegradable substrates such as glucose, acetic acid and ethanol. Under aerobic conditions microorganisms acclimate to the hydrocarbons quite rapidly (3-5 days) while under anoxic conditions the acclimation time required to use nitrate as electron acceptor is considerably longer (20-25 days). Estimation of the kinetic parameters of the Monod model showed that hydrocarbons are characterized by a similar $\mu_{\max }$ than readily biodegradable substrates but by a higher $K_{s}$. This study has also shown the feasibility of investigating microbial growth on hydrocarbons by using respirometric methods.

The results of this study can be applied to the choice and design of biobased strategies for decontamination of oilspills in soils or in waters.

\section{Nomenclature}

$b \quad$ Decay rate constant $\left(\mathrm{day}^{-1}\right)$
$\mathrm{C}_{\mathrm{O}_{2}}^{*}$ Saturated concentration of dissolved oxygen $\left(\mathrm{kgO}_{2} / \mathrm{m}^{3}\right)$

$\mathrm{C}_{\mathrm{O}_{2}} \quad$ Solubility of oxygen under working conditions $\left(\mathrm{kgO}_{2} / \mathrm{m}^{3}\right)$

DO Dissolved oxygen $\left(\mathrm{kgO}_{2} / \mathrm{m}^{3}\right)$

$K_{L} a$ Overall oxygen transfer coefficient $\left(\mathrm{day}^{-1}\right)$

$K_{O 2}$ Oxygen half saturation constant $\left(\mathrm{kg} / \mathrm{m}^{3}\right)$

$K_{s} \quad$ Substrate half saturation constant $\left(\mathrm{kgCOD} / \mathrm{m}^{3}\right)$

$r_{\text {end }}$ Rate of endogenous metabolism (kgbiomass $/ \mathrm{m}^{3}$ day)

$r_{\mathrm{O} 2}$ Rate of oxygen consumption $\left(\mathrm{kgO}_{2} / \mathrm{m}^{3}\right.$ day $)$

$r_{s} \quad$ Rate of substrate consumption ( $\mathrm{kgCOD} / \mathrm{m}^{3}$ day)

$r_{X} \quad$ Rate of biomass growth (kgbiomass/m $\mathrm{m}^{3}$ day)

$\mathrm{S}$ Substrate concentration $\left(\mathrm{kgCOD} / \mathrm{m}^{3}\right)$

$\mathrm{X} \quad$ Biomass (expressed as $\mathrm{kgVSS} / \mathrm{m}^{3}$ )

VFA Volatile fatty acids

$Y_{(X / S)}$ Cell yield coefficient (kgbiomass/kgCOD)

$\mu_{\max }$ Maximum specific growth rate $\left(\mathrm{day}^{-1}\right)$.

\section{References}

[1] Brassington, K.J., Hough, R.L., Paton, G.I., Semple, K.T., Risdon, G.C., Crossley, J., Hay, I., Askari, K. and Pollard, S.J., (2007) Weathered hydrocarbon wastes: a risk management primer, Critical Reviews in Environmental Science and Technology, 37 (3), pp. 199-232.

[2] MacLeod, C.J., Morriss, A. and Semple, K.T., (2001). The role of microorganisms in ecological risk assessment of hydrophobic organic contaminants in soils.

[3] Harayama, S., Kasai, Y. and Hara, A., (2004). Microbial communities in oil-contaminated seawater, Current Opinion in Biotechnology, 15 (3), pp. 205-214.

[4] Gersberg, R.M., Dawsey, W.J. and Bradley, M.D., (1993). Nitrate enhancement of in - situ bioremediation of monoaromatic compounds in groundwater, Remediation Journal, 3 (2), pp. 233-245.

[5] Venosa, A.D., Campo, P. and Suidan, M.T., (2010). Biodegradability of lingering crude oil 19 years after the Exxon Valdez oil spill, Environmental Science \& Technology, 44 (19), pp. 7613-7621.

[6] Nicol, J., Wise, W.R., Molz, F.J. and Benefield, L.D., (1994). Modeling biodegradation of residual petroleum in a saturated porous column, Water Resources Research, 30 (12), pp. 3313-3325.

[7] Sarioglu, M.S. and Copty, N.K., (2008). Modeling the enhanced bioremediation of organic contaminants in pyrite-containing aquifers, Transport in Porous Media, 75 (2), pp. 203-221.

[8] Monod, J., (1949). The growth of bacterial cultures, Annual Reviews in Microbiology, 3 (1), pp. 371-394.

[9] Grady, C., (1985). Biodegradation: its measurement and microbiological basis, Biotechnology and Bioengineering, 27 (5), pp. 660-674.

[10] Dang, J.S., Harvey, D.M., Jobbagy, A. and Grady Jr, C.L., (1989). Evaluation of biodegradation kinetics with respirometric data, Research Journal of the Water Pollution Control Federation, pp. 1711-1721.

[11] Stieber, M., Werner, P. and Frimmel, F., (1994). Investigations on the microbial degradation of polycyclic aromatic hydrocarbons (PAHs) in contaminated soils, Bioreclamation of Chlorinated and Polycyclic Hydrocarbon Compounds Ed.Hinchee, RE and Leeson, A, pp. 164-171.

[12] Bartram, A.K., Jiang, X., Lynch, M.D., Masella, A.P., Nicol, G.W., Dushoff, J. and Neufeld, J.D., (2014). Exploring links between pH and bacterial community composition in soils from the Craibstone Experimental Farm, FEMS Microbiology Ecology, 87 (2), pp. 403-415.

[13] Benedek, A. and Heideger, W.J., (1971). Effect of additives on mass transfer in turbine aeration, Biotechnology and Bioengineering, 13 (5), pp. 663-684.

[14] Sheppard, J.D., (1989). Feedback Control and the Continuous Phasing of Microbial Cultures. 
[15] Poster, D.L., Schantz, M.M., Sander, L.C. and Wise, S.A., (2006). Analysis of polycyclic aromatic hydrocarbons (PAHs) in environmental samples: a critical review of gas chromatographic (GC) methods, Analytical and Bioanalytical Chemistry, 386 (4), pp. 859-881.

[16] Ying, L., Hongwei, J., Huizhen, X. and Li, L., (2006). A new spectrophotometric method for measuring COD of seawater, Journal of Ocean University of China, 5 (2), pp. 137-140.

[17] Marino, F., Karp, J. and Cooper, D., (1998). Biomass measurements in hydrocarbon fermentations, Biotechnology Techniques, 12 (5), pp. 385-388.

[18] Dionisi, D., (2017). Biological Wastewater Treatment Processes: Mass and Heat Balances. CRC Press.

[19] Kindred, J.S. and Celia, M.A., (1989). Contaminant transport and biodegradation: 2. Conceptual model and test simulations, Water Resources Research, 25 (6), pp. 1149-1159.

[20] Gödeke, S., Vogt, C. and Schirmer, M., (2008). Estimation of kinetic Monod parameters for anaerobic degradation of benzene in groundwater, Environmental Geology, 55 (2), pp. 423-431.

[21] Mohamed, M. and Hatfield, K., (2011). Dimensionless parameters to summarize the influence of microbial growth and inhibition on the bioremediation of groundwater contaminants, Biodegradation, 22 (5), pp. 877-896.

[22] Metcalf, E., (1991). Wastewater Engineering: Treatment, Disposal, and Reuse, 3

[23] Bailey, J. and Ollis, D., (1986). Applied enzyme catalysis, Biochemical Engineering Fundamentals, 2 pp. 157-227.

[24] Molz, F.J., Widdowson, M. and Benefield, L., (1986). Simulation of microbial growth dynamics coupled to nutrient and oxygen transport in porous media, Water Resources Research, 22 (8), pp. 1207-1216.

[25] Schirmer, M., Molson, J.W., Frind, E.O. and Barker, J.F., (2000). Biodegradation modelling of a dissolved gasoline plume applying independent laboratory and field parameters, Journal of Contaminant Hydrology, 46 (3), pp. 339-374.

[26] Hao, O.J., Richard, M.G., Jenkins, D. and Blanch, H.W., (1983) The half - saturation coefficient for dissolved oxygen: A dynamic method for its determination and its effect on dual species competition, Biotechnology and Bioengineering, 25 (2), pp. 403-416.

[27] Bruce, E.R. and Perry, L.M., (2001). Environmental biotechnology: principles and applications, New York: McGrawHill, 400.

[28] Fritsche, W. and Hofrichter, M., (2008). Aerobic degradation by microorganisms, Biotechnology Set, Second Edition, pp. 144-167.

[29] Olson, J.J., Mills, G.L., Herbert, B.E. and Morris, P.J., (1999). Biodegradation rates of separated diesel components, Environmental Toxicology and Chemistry, 18 (11), pp. 2448-2453.

[30] Lal, B. and Khanna, S., (1996). Degradation of crude oil by Acinetobacter calcoaceticus and Alcaligenes odorans, Journal of Applied Bacteriology, 81 (4), pp. 355-362.

[31] Setti, L., Pifferi, P.G. and Lanzarini, G., (1995). Surface tension as a limiting factor for aerobic $\mathrm{n}$ - alkane biodegradation, Journal of Chemical Technology and Biotechnology, 64 (1), pp. 41-48.

[32] Thomas, J.M., Yordy, J.R., Amador, J.A. and Alexander, M., (1986). Rates of dissolution and biodegradation of water-insoluble organic compounds, Applied and Environmental Microbiology, 52 (2), pp. 290-296.

[33] Ladygina, N., Dedyukhina, E. and Vainshtein, M., (2006). A review on microbial synthesis of hydrocarbons, Process Biochemistry, 41 (5), pp. 1001-1014.

[34] Zilber, I.K., Rosenberg, E. and Gutnick, D., (1980). Incorporation of $\mathrm{P}$ and Growth of Pseudomonad UP-2 on n-Tetracosane, Applied and Environmental Microbiology, 40 (6), pp. 1086-1093.

[35] Miller, T.L. and Johnson, M.J., (1966). Utilization of normal alkanes by yeasts, Biotechnology and Bioengineering, 8 (4), pp. 549-565.

[36] Bai, G., Brusseau, M.L. and Miller, R.M., (1997). Biosurfactantenhanced removal of residual hydrocarbon from soil, Journal of Contaminant Hydrology, 25 (1), pp. 157-170.

[37] Beal, R. and Betts, W., (2000). Role of rhamnolipid biosurfactants in the uptake and mineralization of hexadecane in Pseudomonas aeruginosa, Journal of Applied Microbiology, 89 (1), pp. 158-168.

[38] Churchill, P.F. and Churchill, S.A., (1997). Surfactant-enhanced biodegradation of solid alkanes, Journal of Environmental Science \& Health Part A, 32 (1), pp. 293-306.
[39] Thibault, G. and Elliott, N., (1979). Accelerating the biological clean up of hazardous materials spills, Proceedings Oil and Hazards Materials.Spills: Prevention-Control-Cleanup-RecoveryDisposal.

[40] Peng, Y., Yong, M. and Wang, S., (2007). Denitrification potential enhancement by addition of external carbon sources in a predenitrification process, Journal of Environmental Sciences, 19 (3), pp. 284-289.

[41] O’Reilly, C. and Colleran, E., (2005). Toxicity of nitrite toward mesophilic and thermophilic sulphate-reducing, methanogenic and syntrophic populations in anaerobic sludge, Journal of Industrial Microbiology and Biotechnology, 32 (2), pp. 46-52.

[42] So, C.M. and Young, L.Y., (2001). Anaerobic biodegradation of alkanes by enriched consortia under four different reducing conditions, Environmental Toxicology and Chemistry, 20 (3), pp. 473-478.

[43] Callaghan, A.V., Tierney, M., Phelps, C.D. and Young, L.Y., (2009). Anaerobic biodegradation of n-hexadecane by a nitratereducing consortium, Applied and Environmental Microbiology, 75 (5), pp. 1339-1344.

[44] Grady Jr, C.L., Daigger, G.T., Love, N.G. and Filipe, C.D., (2011) Biological Wastewater Treatment. CRC press.

[45] Jones, D., Head, I., Gray, N., Adams, J., Rowan, A., Aitken, C. Bennett, B., Huang, H., Brown, A. and Bowler, B., (2008). Crude-oil biodegradation via methanogenesis in subsurface petroleum reservoirs, Nature, 451 (7175), pp. 176-180.

[46] Wang, L., Mbadinga, S., Li, H., Liu, J., Yang, S. and Mu, B., (2010). Anaerobic degradation of petroleum hydrocarbons and enlightenment of the prospects for microbial bio-gasification of residual oil, Microbiology, 37, pp. 96-102.

[47] Aichinger, G., Grady Jr, C.L. and Tabak, H.H., (1992). Application of respirometric biodegradability testing protocol to slightly soluble organic compounds, Water Environment Research, pp. 890-900.

[48] Van Hamme, J. and Ward, O., (2001). Volatile hydrocarbon biodegradation by a mixed-bacterial culture during growth on crude oil, Journal of Industrial Microbiology and Biotechnology, 26 (6), pp. 356-362.

[49] Plohl, K., Leskovsek, H. and Bricelj, M., (2002). Biological degradation of motor oil in water, Acta Chimica Slovenica, 49 (2), pp. 279-290.

[50] Walker, J.D. and Colwell, R.R., (1974). Microbial petroleum degradation: use of mixed hydrocarbon substrates, Applied Microbiology, 27 (6), pp. 1053-1060.

[51] Grady, J.(.L. and Lim, H.C., (1980). Biological Wastewater Treatment: Theory and Applications. Marcel Dekker, Incorporated.

[52] Barford, J.P. and Hall, R., (1981). A mathematical model for the aerobic growth of Saccharomyces cerevisiae with a saturated respiratory capacity, Biotechnology and Bioengineering, 23 (8), pp. 1735-1762.

[53] Bijkerk, A. and Hall, R., (1977). A mechanistic model of the aerobic growth of Saccharomyces cerevisiae, Biotechnology and Bioengineering, 19 (2), pp. 267-296.

[54] Peringer, P., Blachere, H., Corrieu, G. and Lane, A., (1974). A generalized mathematical model for the growth kinetics of Saccharomyces cerevisiae with experimental determination of parameters, Biotechnology and Bioengineering, 16 (4), pp. 431-454.

[55] Henze, M., Gujer, W., Mino, T. and Van Loosdrecht, M., (2000). Activated Sludge Models ASM1, ASM2, ASM2d and ASM3. IWA publishing.

[56] Geng, X., Boufadel, M.C. and Wrenn, B., (2013). Mathematical modeling of the biodegradation of residual hydrocarbon in a variably-saturated sand column, Biodegradation, 24 (2), pp. 153-163.

[57] Choi, D.H., Hori, K., Tanji, Y. and Unno, H., (1999). Microbial degradation kinetics of solid alkane dissolved in nondegradable oil phase, Biochemical Engineering Journal, 3 (1), pp. 71-78.

[58] Mulder, H., Breure, A. and Rulkens, W., (2001). Prediction of complete bioremediation periods for PAH soil pollutants in different physical states by mechanistic models, Chemosphere, 43 (8), pp. 1085-1094. 